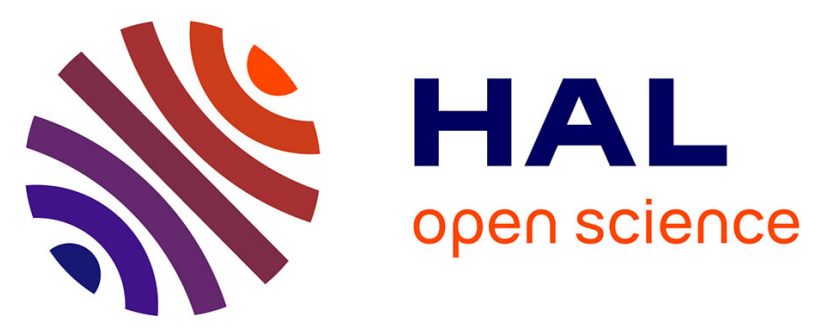

\title{
Developmental dynamics of SES-related differences in children's production of obligatory and variable phonological alternations
}

\author{
Jean-Pierre Chevrot, Aurélie Nardy, Stéphanie Barbu
}

\section{To cite this version:}

Jean-Pierre Chevrot, Aurélie Nardy, Stéphanie Barbu. Developmental dynamics of SES-related differences in children's production of obligatory and variable phonological alternations. Language Sciences, 2011, 33, pp.180-191. 10.1016/j.langsci.2010.08.007 . hal-00718025v2

\section{HAL Id: hal-00718025}

https://hal.science/hal-00718025v2

Submitted on 19 Jan 2013

HAL is a multi-disciplinary open access archive for the deposit and dissemination of scientific research documents, whether they are published or not. The documents may come from teaching and research institutions in France or abroad, or from public or private research centers.
L'archive ouverte pluridisciplinaire HAL, est destinée au dépôt et à la diffusion de documents scientifiques de niveau recherche, publiés ou non, émanant des établissements d'enseignement et de recherche français ou étrangers, des laboratoires publics ou privés. 
Chevrot, J.-P., Nardy, A. \& Barbu, S. (2011). Developmental dynamics of SES-related differences in children's production of obligatory and variable phonological alternations. Language sciences, 33, 180-191.

\title{
Developmental dynamics of SES-related differences in children's production of obligatory and variable phonological alternations Jean-Pierre CHEVROT ${ }^{\mathrm{a}, \mathrm{b}}$, Aurélie NARDY ${ }^{\mathrm{a}}$, Stéphanie BARBU ${ }^{\mathrm{c}}$
}

a LIDILEM - Laboratoire de Linguistique et Didactique des Langues Étrangères et Maternelles, Université Grenoble 3, BP 25, 38040 Grenoble cedex 9, France.e-mail: jpchevrot@wanadoo.fr, aurelie.nardy@ugrenoble3.fr

b LPNC - Laboratoire de Psychologie et Neurocognition, CNRS \& Université Grenoble 2, BP 47, 38040 Grenoble Cedex 9, France.

c UMR 6552 Éthologie animale et humaine, CNRS \& Université Rennes 1, Campus de Beaulieu, Avenue du Général Leclerc, 35042 Rennes cedex, France.e-mail: stephanie.barbu@univ-rennes1.fr

Corresponding author : Jean-Pierre Chevrot, LIDILEM, BP 25, 38040 Grenoble cedex 9, France. e-mail: jpchevrot@ wanadoo.fr. Tel. : +33 (0) 4764190 46, Fax : +33 (0) 4768243 95

\begin{abstract}
Numerous studies conducted in both the psycholinguistic and sociolinguistic fields have established that the parents' socioeconomic status (SES) influences several aspects of children's language production. Moreover, a number of psycholinguistic studies strongly suggest that these differences are due in part to differences in the nature and the quantity of input that children are exposed to. Despite these advances, in our knowledge, the developmental dynamic of the differences still has to be described and explained. The aim of the current study is to examine this dynamic in the production of liaison, a phonological alternation in French which is, in some cases, obligatory and used in a uniform manner by adults and, in others, a sociolinguistic variable whose frequency of use depends on the speaker's SES. One hundred and eighty-five children aged from 2;3 to 6;0 belonging to two distinct SES groups (higher and lower SES) and subdivided into four age-groups participated in a picture naming task eliciting the production of obligatory and variable liaisons. First, an analysis of the three types of child production (correct liaison, omission, replacement) confirms that the linguistic forms which are present in the input increase with age in children's productions, whereas those which are absent tend to disappear. Second, the evolution of the SES-related differences depends on the uniformity or heterogeneity of usage in the social groups: convergence for obligatory liaison and divergence for variable liaison. The discussion of these findings combines both psycholinguistic and sociolinguistic perspectives since both have stressed the importance of exposure to linguistic forms in the input.
\end{abstract}

Key words: Language acquisition; SES-related difference; Phonological alternation; French liaison; Sociolinguistic variation 


\section{Introduction}

Many studies conducted in the psycholinguistic field have shown that sociocultural factors influence different aspects of children's language production. The socioeconomic status (SES) of the parents has an effect on lexical development from 2 years of age (Bornstein et al., 1998; Hoff, 2002, 2003; Hoff et al., 2002), and on the mean length of utterances and number of lexical types and tokens at the age of 3 years (Dollaghan et al., 1999) and from 2 to 4 years (Le Normand et al., 2008), as well as on the proportion of complex sentences at the age of 4-5 years (Huttenlocher et al., 2002). On most of the examined verbal measures, children from higher-SES families perform better than children from lower-SES families. However, the evolution of the differences with age has not been studied in detail.

A growing body of evidence shows that this relation between SES and children's language is attributable in part to differences in the speech that parents address to their children. These differences in the input take two different forms.

First, certain types of socio-pragmatic functions, linguistic units or constructions are not equally represented in the input received by children from different social backgrounds. The number of word types and topic-continuing replies (Hoff, 2003), the number of sentence types and word types, the number of words and noun phrases per sentence, as well as the ratio of multiclause sentences (Huttenlocher et al., 2007) are higher in the speech that parents from higher-SES groups address to their children under the age of three years. As noted by Huttenlocher et al. (2007), it is necessary to distinguish between various types of measures of input differences. Certain criteria assess the diversity in caregiver speech (number of types), whereas others assess the degree of syntactic complexity (number of phrases per sentence, ratio of multiclause sentences). Moreover, it is important to recognize that some of these criteria involve an opposition between two types of forms or functions (e.g. complex vs simple sentences), whereas others, such as the measures of diversity, cannot be considered in such a polarized manner (e.g. number of types, number of phrases per sentence).

Second, several studies have shown that the overall quantity of input provided to a child varies according to the social background. Hart and Risley (2003) estimate that the number of word tokens produced in a year in a child's language input is 11.2 million, 6.5 and 3.2 million in higher-SES, middle-SES and lower-SES families respectively. Other linguistic measures confirm that parents from higher SES categories address a larger volume of speech to children aged under three years: number of word tokens, number of utterances (Hoff, 2003; Huttenlocher et al., 2007), number of sentences (Huttenlocher et al., 2007). These differences 
in the quantity of input mean that children from higher-SES families hear all the different linguistic forms and functions more frequently.

These two types of differences in the input could have different impacts on the construction of linguistic knowledge and consequently on the age-related development in the differences in the output produced by children from different social groups. In this paper, we will consider two cases. The first case concerns competing pairs of forms or functions. Given that the elements of the pair occur with different frequencies in the various social groups, the cumulative effect of long-term exposure to the language environment should continuously and differentially reinforce the availability of each element in each social group. The difference in the output produced by children from different social backgrounds is thus expected to increase with age. The second case relates to the linguistic forms or functions which are not elements of a competing pair. Due to the difference in the overall quantity of input, children from higher-SES families encounter these elements more often and have a greater opportunity to learn their functioning. It follows that, at an early age, they should use these elements more correctly than children from lower-SES families, thus leading to early differences between the SES groups. However, once children from the lower-SES families have encountered these elements a sufficient number of times, they too will learn their functioning. The long-term cumulative effect of the input should therefore mean that these early differences decrease during development.

\subsection{The contribution of sociolinguistics}

When attempting to document these two types of influence on children's language, it is useful to take account of the findings of sociolinguistic research into linguistic variation. Since the early work conducted by Labov (1972a; 1972b), variationist studies have concentrated on describing the differences in the use of the so-called linguistic variables, i.e. the points of variation which enable speakers to say the same thing in different ways, with these variants being "identical in reference or truth value, but opposed in their social and/or stylistic significance" (Labov, 1972b, pp. 271). Numerous linguistic variables have been described in a number of languages. For instance, at the phonological level, speakers from New-York studied by Labov (1972b) may or may not produce the consonant $/ \mathrm{r}$, present in car or four in postvocalic positions. At the morphological level, French speakers may optionally omit the preverbal morpheme of the negation ne...pas which surrounds the verb (Armstrong, 2002). 
Four decades of sociolinguistic research have established that these points of variation are subject to social judgment in adults. In short, judgment tasks reveal that the so-called standard variants are generally associated with social prestige, high education level, professional ambition and efficiency, whereas the so-called non-standard variants are linked to social skills, solidarity and loyalty towards the native group (Lafontaine, 1986; Trudgill, 1975). Furthermore, many studies in different languages have shown that the production of the standard variants is organized according to social factors. On the one hand, the standard variants are more frequent in the speech of higher-SES adult speakers (Labov, 1972b, 2001; Trudgill, 1995). On the other, their frequency also depends on the context of the exchange which may involve formal situations (classroom interaction, medical consultation) or informal ones (family meal, peer group interaction), or change across successive periods in the same situation as a function of local parameters, for example when the topic of conversation or the interlocutor changes (Coupland, 2007). The results concerning the patterns of sociolinguistic variation are therefore well established in adults.

Since adult speech is characterized by this type of variation, children come into contact with it at an early age. The question of when and how children learn to use these variants has been studied only intermittently over the last four decades and no consensus has been reached concerning the age of appearance of sociolinguistic patterns and their changes over the course of development (Chevrot et al., 2000). Despite these discrepancies, a review of the literature makes it possible to identify the earliest age at which adult-like patterns have been observed for specific phonological variables. It should be noted that, in variationist research in general as well as in the present study, quantitative research has focused on features at the phonological level which ideally fulfill the four criteria used to define the most useful sociolinguistic variables: high frequency, immunity from deliberate control, integration in a larger linguistic structure, possibility of quantification on a linear scale (Labov, 1964).

The earliest adaptations to the context of exchange during childhood have been observed among three-year-old children by Roberts (1994) and Smith et al. (2007). These authors have shown that children are able to select variants according to the type of interaction in which they are involved. The earliest age at which an influence of the parents' SES has been observed is between three and five years. This result relates to the variable production of the intervocalic /d/ in Spanish-speaking children recorded during an interview involving narrative tasks (Díaz-Campos, 2005). These findings lead to the conclusion that the first manifestations of adult-like differences in children's use of linguistic variables occur at an early age. 
However, as has already been observed in connection with psycholinguistic studies, the way social differences change as a function of age is unknown.

Thus, although studies conducted in both the sociolinguistic and psycholinguistic fields have revealed SES-related differences in children's language use, the evolution of these differences during development is not clear. Moreover, the linguistic features studied in the two areas are different. On the one hand, we find specific sociolinguistic variants whose usage varies according to social group, which are subject to social judgment and which are described in terms of a limited set of competing variants. On the other, we find measures of general abilities (e.g. vocabulary size, grammatical complexity), which are not per se associated with any social value and cannot be reduced to a limited set of competing variants. Despite these differences, it would be beneficial to be able to draw the two areas closer together. Indeed, the sociolinguistic variables are a perfect illustration of competing pairs of forms which are unevenly distributed across the social groups. Thus if we could find a linguistic feature which acts as a sociolinguistic variable in certain linguistic contexts, while also being used uniformly within the speech community in other contexts, we should be able to explore in detail how children's productions are influenced by the two types of SES-related differences in the input: $1 /$ differences based on pairs of competing forms, the frequency of which varies according to the parents' SES; 2/ differences based on a single linguistic form, the frequency of which depends, in each social group, on the overall quantity of speech addressed to the child. Liaison in French is one such phonological alternation which possesses precisely these two characteristics. As we will see in the next section, variable liaison is a well-known sociolinguistic variable in adult speakers in that it is used differently according to SES and context, while obligatory liaison is not affected by these factors and all adults produce it systematically irrespective of their social characteristics and the specific speech situation. Our aim here is to investigate whether and, if so, when social differences emerge in the production of these two types of liaison and how they evolve during the course of development. In the following section, we shall start by presenting the functioning of the two types of liaison in adults from different SES groups. Taking this as our starting point, we will formulate hypotheses regarding what should be observed in the production of children who are exposed to the obligatory and variable liaison in different social backgrounds.

\subsection{The functioning of liaisons in adults}

Liaison is a frequent phonological alternation in French: a liaison context occurs every 16 words in adult speech (Boë and Tubach, 1992). To produce a liaison, it is necessary to insert a 
consonant between two words (word1 and word2) during connected speech. For this consonant to appear, word 2 must begin with a vowel when pronounced in isolation. For instance, the French word un ('a/one') (word1) is not followed by a liaison when used at the end of an utterance (J'en choisis un [3 $\tilde{a} \int$ waziõe] 'I choose one') or before a consonant-initial

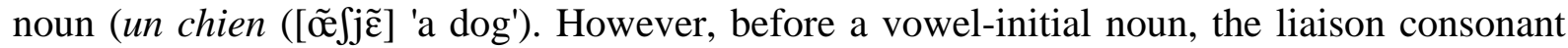

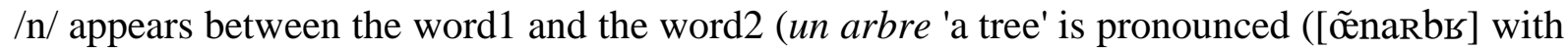
the $/ \mathrm{n} /$ liaison between $u n$ and arbre). When the liaison consonant is produced, it forms a syllable with the initial vowel of the following word: for instance, the syllabification of the

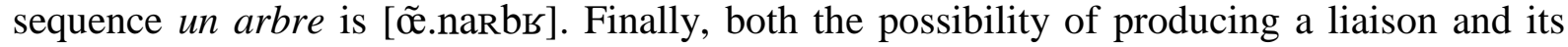
phonetic nature (/n/, /z/ and /t/ in 99.7\% of cases, Boë \& Tubach, 1992) depend on the word 1. For example, the word1s un 'a/one' or aucun 'none' both trigger an /n/ liaison, the word1s petit 'small' or grand 'large' a /t/ liaison, the word1s gros 'big' or deux 'two' a /z/ liaison, whereas joli 'pretty' or beau 'beautiful' in the singular do not trigger any liaison.

The liaison contexts are divided into two categories: the contexts where the liaison is obligatory and the contexts where it is variable. Our research is based on the classification established by Durand and Lyche (2008), which confirms the results of Booij and De Jong (1987). Based on observations of the speech of 100 French speakers from different geographical areas and different social backgrounds, Durand and Lyche (2008) found that liaison appears to be obligatory only after preverbal clitics (ils arrivent [ilzasiv] 'they

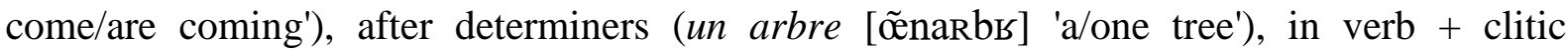
inversions (Comment dit-on? [komãditõ] 'how do we say?') and in certain frozen expressions (tout à fait [tutafe] 'quite'). Other liaison contexts appear to be variable with individual production levels of less than $100 \%$. For example, between an adjective and a noun, a liaison consonant may or may not be produced by adult speakers: gros éléphant 'big elephant' is pronounced either [gвоzelefã] with a /z/ liaison or [gвоеlefã] without any liaison.

Variable liaison is known to be a stratified sociolinguistic variable in adults. A number of studies combine to show that the frequency of realization of this type of liaison varies as a function of the speaker's speech style and sociodemographic characteristics. All the studies that have included the speaker's SES as a factor have found that members of higher-SES groups produce more variable liaisons than individuals from lower-SES groups (Ashby, 1981; Booij and De Jong, 1987; De Jong, 1991, 1994). For example, De Jong (1991) observed significant SES-related differences in the production rates of variable liaisons in the speech of 45 adults: $61.6 \%$ upper middle class, $29.6 \%$ lower working class. In a study of five socio- 
economic groups, Booij and De Jong (1987) found a regular stratification in the production rates of six variable liaison contexts. The results relating to gender are unclear. De Jong (1991; 1994) has observed that women produce more variable liaisons than men, whereas Ashby (1981) and Green and Hintze (1990) found the reverse pattern and Moisset (2000) no difference at all. Finally, in all the available studies, speech style has been shown to be a regular factor influencing the production of variable liaisons: the more formal the speech situation, the more frequent the appearance of a liaison (£gren, 1973; Booij and De Jong, 1987; Lucci, 1983; Moisset, 2000).

Although none of the numerous corpus studies has analyzed liaison in the speech addressed to children, the available results strongly suggest that children from higher-SES groups hear more realized variable liaisons than children from lower-SES groups. In addition, it is important to keep in mind that, even though obligatory liaisons are always produced by all adults irrespective of social background, higher-SES children will probably hear these liaisons more often due to the overall SES-related differences in the quantity of input. These considerations enable us to make predictions about children's production of correct liaisons and their liaison errors.

\subsection{Predictions about children's production}

Experimental and corpus-based data have clearly demonstrated that children produce three types of forms in liaison contexts (Chevrot et al., 2007; Chevrot et al., 2009; Dugua, 2006):

- adult-like liaisons: for example, /z/ liaison in the obligatory context les arbres 'the trees' ([lezarbь]), /z/ liaison in the variable context gros éléphant 'big elephant' ([gьоzelefã]) ;

- replacement errors: for example, /n/ liaison instead of the expected /z/ in the obligatory context les arbres ([lenarbs]), /t/ liaison instead of the expected /z/ in the variable context gros éléphant ([gьоtelefã]);

- omissions: for example, no liaison consonant in the obligatory context les arbres ([leaRbь]) or in the variable context gros éléphant ([gьоеlefã]).

Our predictions are based on two assumptions. First, among the three types of production (correct, replacement, omission), those which are present in the input should become gradually more frequent in children's productions, whereas the transitional forms (child errors), which are not present in the input, should gradually disappear, whatever the child's social background. It should be emphasized that the absence of liaison in the obligatory contexts is considered to be an error (an omission error) in the same way as the replacement 
error, whereas it is one of the two possible variants used by adults in the variable contexts. Second, we assume that the forms which are more frequent in the input should be learned more rapidly. These considerations lead us to make certain predictions about the age-related changes in the three types of child production for both obligatory and variable liaisons and for different social backgrounds.

As far as the correct production of obligatory liaison is concerned, we predict that the productions of children from different social backgrounds should converge with age. In effect, the obligatory liaisons are systematically produced in the different social environments. Due to differences in the overall quantity of input, higher-SES children should memorize and generalize the functioning of obligatory liaison more rapidly. Consequently, they should produce a larger number of correct liaisons earlier in development. However, the cumulative effect of the input should allow lower-SES children to attain the same level of correct production later in development, thus leading to the progressive disappearance of the early SES-related differences. As far as the omission and replacement of obligatory liaisons are concerned, these types of production are not found in the speech which adults address to children, whatever the social background. They should thus progressively disappear from the productions of all children.

As regards the correct realization and the omission of variable liaisons, we predict that the productions of children from different social backgrounds should diverge. In effect, although both omissions and realizations are present in the input heard by children, the two competing variants are unequally represented in the different social backgrounds. The cumulative effect of the input should therefore continuously and differentially reinforce the two variants in the different social groups. As a result, the SES-related differences in production should increase during the course of development. More precisely, higher-SES children should progressively produce more of these liaisons than lower-SES children while the opposite should be true for omissions. Finally, given that replacements of variable liaisons do not occur in adult speech irrespective of social background, they should progressively disappear from the productions of all children.

To test these predictions, we carried out a picture naming task which required the production of obligatory and variable liaisons by a sample of French-speaking children aged between 2;3 and 6;0 whose parents' occupations contrasted greatly in terms of SES. 


\section{Method}

\subsection{Participants}

Our sample consisted of 185 children (93 girls and 92 boys), French native speakers, aged from $2 ; 3$ to $6 ; 0$ (mean age $\pm \mathrm{SD}=50.7 \pm 11.9$ months). They were chosen on the basis of both their parents' occupations (available for consultation subject to each school's headmaster's special permission), which enabled us to position them on a binary social scale - higher SES versus lower SES - which defined the family's SES. The parents' occupations were classified in accordance with the INSEE $^{1}$ categorization (Desrosières and Thévenot, 1988). Children with two parents belonging to group 3 of the INSEE categorization (e.g., teachers and scientific professions, senior managers, engineers) were considered to be high SES participants. Children with both parents belonging to group 6 (industrial, trades, agricultural workers and drivers) were classified as lower SES. When one of the parents was unemployed (i.e., did not work outside the household), only the occupation of the other working parent was considered.

For the analyses, we divided the children into four age groups (Table 1): 2-3 years old (2;3 to $3 ; 2$, mean age $\pm \mathrm{SD}=34.9 \pm 2.6$ months), $3-4$ years old ( $3 ; 3$ to $4 ; 0,43.3 \pm 2.7$ months), $4-5$ years old ( $4 ; 1$ to $5 ; 0,54.2 \pm 3.3$ months), 5-6 years old ( $5 ; 1$ to $6 ; 0,66.3 \pm 3.4$ months). These four age groups were chosen to correspond to the four grades in French nursery school since all the children with the exception of 3 of the youngest attended school regularly.

\section{Insert table 1 here}

\subsection{Task and Procedure}

A picture naming task was designed to induce children to produce obligatory and variable liaisons. The children were asked to produce 24 word1-word2 sequences in response to pictures of animals or objects.

The word 2 s consisted of six nouns starting with a vowel (i.e., inducing a liaison): ours 'bear' - arbre 'tree' - avion 'plane' - escargot 'snail' - éléphant 'elephant' - ordinateur 'computer'. These nouns are familiar to young children. In children aged between 3 and 5 years, the corresponding pictures are known to be named correctly in $90 \%$ to $100 \%$ of cases (Cannard et al., 2006), with the exception of ours for which the rate is below $80 \%$ at the age

\footnotetext{
${ }^{1}$ INSEE: Institut National de la Statistique et des Etudes Economiques (French National Institute of Statistic and Economic Studies).
} 
of 3-4 years, and ordinateur which is not present in the database. To improve success in the naming task, we used the picture of a bear previously used by Dugua (2006) in a similar liaison elicitation task. This picture results in the correct naming of the noun ours in $85 \%$ of trials conducted in children aged from 2 to 6 years. To the six vowel-initial word 2 s, we added six consonant-initial nouns (i.e. inhibiting the liaison): ballon 'ball', lit 'bed', cochon 'pig', singe 'monkey', camion 'lorry', balai 'broom'.

The naming task induced the production of these word $2 \mathrm{~s}$ in combination with two types of word1s: on the one hand, the determiners un 'a/one' and deux 'two', which induce a $/ \mathrm{n} / \mathrm{and}$ a /z/ liaison respectively, and on the other, the adjectives petit 'small' et gros 'big', which induce $/ \mathrm{t} /$ and $/ \mathrm{z} /$. According to the studies of spoken French (see above), the liaison following determiners such as un 'a'/'one' and deux 'two' is obligatory, whereas the liaison after prenominal adjectives such as petit 'small' and gros 'big' is variable. To elicit the production of obligatory liaisons after the determiners un 'a'/'one' and deux 'two', the animals and objects were depicted once in six pictures and twice in six other pictures. To induce variable liaison after the adjectives, the items were represented in a large size in six pictures (word1: gros 'big') and in a small size in six other pictures (word1: petit 'small').

In all, the children had to produce 48 word1-word 2 sequences. Twelve target sequences contained an obligatory liaison. These were formed with a determiner and a vowel-initial noun (six sequences with the determiner $u n$ and six with deux). The target items were interspersed with twelve filler trials in which the liaison was blocked. These were constructed using the same determiners and a consonant-initial noun. Another twelve target sequences contained a variable liaison. These resulted from the combination of an adjective and a vowelinitial noun (six sequences with the adjective petit and six with gros). In order to minimize the effect of priming between successive productions, these target sequences also alternated with filler trials formed using the same adjectives and a consonant-initial noun.

The children were tested individually at school. The experimenter asked the children, 'What is there in this picture?' and the children needed to give an answer of the type determiner + noun (e.g., two bears) or adjective + noun (e.g., small bear). Half of the children had to produce the twenty-four determiner + noun sequences (obligatory liaisons) followed by the twenty-four adjective + noun sequences (variable liaisons) while the other half followed the reverse order. Within each block of sequences, the order of presentation of the pictures was randomized and changed for each child, although the alternation between target sequences and filler trials was maintained. 


\subsection{Statistical analyses}

For both the obligatory and variable liaisons, one score was computed for each type of production (correct liaison, omission, replacement). To calculate the six percentages, both non-responses and atypical responses were removed from the overall number of word1-word2 sequences that the children had to produce. Non-responses corresponded to cases when children remained silent. Atypical responses were errors in which the child cut off the initial vowel of the word2 (e.g., [dølefã] for deux éléphants 'two elephants') or named the wrong word2 (e.g., mammouth 'mammoth' instead of éléphant 'elephant'). The correct liaison score was therefore the number of liaisons produced with the correct consonant (e.g. [døzuss] 'two bears') divided by the total number of productions (the twelve target liaisons minus nonresponses and atypical responses). The replacement score was the number of liaison consonant substitutions (e.g. [dønuss] instead of [døzuss]) divided by the actual total number of productions. The omission score was the number of missing liaisons (e.g. [døuss], without any liaison, instead of [døzurs]) divided by the total number of productions.

Two-way analyses of variance were conducted on each of the six scores in order to test the main effects of SES (2 groups) and age (4 groups) and their interaction after transformations of the data to correct for variance heterogeneity (Sokal and Rohlf, 1981). Fisher's PLSD were performed for post hoc comparisons.

\section{Results for obligatory liaisons}

\subsection{Correct production of obligatory liaisons}

The general evolution with age of the mean correct production percentages by age and by SES can be seen in Figure 1. Age significantly influenced the correct production of obligatory liaisons $(F(3,177)=24.49, \mathrm{p}<.001)$. Moreover, we also noted an impact of SES, with higherSES participants producing significantly more correct obligatory liaisons than lower-SES children $(F(1,177)=31.08, p<.001)$. Finally, there was a significant interaction between age range and SES $(F(3,177)=4.31, \mathrm{p}=.005)$. The difference between higher-SES and lowerSES children was significant in age range $1(\mathrm{p}<.0001)$, marginally significant in age range 2 $(\mathrm{p}=.0902)$, significant in age range $3(\mathrm{p}=.0187)$, and not significant in age range $4(\mathrm{p}=$ .2138). Moreover, the correct liaison rate increased between age 1 and age 4 , not only for the sample as a whole $(\mathrm{p}<.0001)$ but also for the lower-SES $(\mathrm{p}<.0001)$ and higher-SES $(\mathrm{p}<.0002)$ children. 
Insert Figure 1 here

Figure 1- Obligatory liaison: Evolution with age of correct productions in higher and lowerSES children (mean percentages + standard errors)

\subsection{Omission errors for obligatory liaisons}

A two-way ANOVA showed that both age $(\mathrm{F}(3,177)=3.11, \mathrm{p}=.027)$ and SES $(\mathrm{F}(1,177)=4.80, \mathrm{p}=.029)$ influenced the rate of omission errors (see Figure 2). The interaction was significant $(\mathrm{F}(3,177)=5.15, \mathrm{p}=.001)$. The overall production of omission errors was greater in lower-SES children. However, the difference did not remain constant in the various age ranges. In age range 1, lower-SES children produced significantly more errors than the more privileged children $(\mathrm{p}<.0003)$. No significant difference occurred in age range $2(\mathrm{p}=.15)$ or age range $3(\mathrm{p}=.93)$. In age range 4 , the difference was marginally significant $(\mathrm{p}=.0895)$. This age-related fluctuation in SES differences was due to a marginally significant increase in the error rate in higher-SES children between age ranges 1 and $2(\mathrm{p}=.10)$, followed by a significant decrease between age ranges 2 and $4(p<.006)$. This developmental profile suggests a regularization process, with an increase in the number of occurrences followed by a decline. However, if we consider the general evolution of the error rate between age range 1 and age range 4, the values declined for the lower-SES children $(p<.002)$ and for the sample as a whole $(\mathrm{p}<.003)$, but not for the higher-SES children $(\mathrm{p}=.312)$ for whom the error levels were very low as early as age group 1.

\section{Insert Figure 2 here}

Figure 2 - Obligatory liaison: Evolution with age of omission in higher and lower-SES children (mean percentages + standard errors)

\subsection{Replacement errors for obligatory liaisons}

As far as replacement errors are concerned, the effects of age $(F(3,177)=20.84, p<.001)$ and SES $(\mathrm{F}(1,177)=29.54, \mathrm{p}<.001)$ were significant as was the interaction $(\mathrm{F}(3,177)=3.02$, $\mathrm{p}=.030$ ). Lower-SES children produced more replacement errors both across the sample as a whole and in the ages ranges 1,2 and $3(\mathrm{p}=.0076, \mathrm{p}<.0001, \mathrm{p}=.0003$, respectively). In age range 4 , the error rates tended toward zero and the difference between the social groups was no longer significant $(\mathrm{p}=.7581)$. The decrease in the error rate between the age ranges 1 and 
4 was significant for the sample as a whole $(\mathrm{p}<.0001)$ and for both lower-SES $(\mathrm{p}<.0001)$ and higher-SES $(\mathrm{p}<.0001)$ children.

Insert Figure 3 here

Figure 3 - Obligatory liaison: Evolution with age of replacement errors in higher and lowerSES children (means percentages + standard errors)

\subsection{Conclusion for obligatory liaisons}

First, the results showed that the correct production scores obtained by the two SES groups converged with age. The interaction between age and SES was significant and the higher-SES children produced significantly more correct liaisons in the youngest age group, but not in the oldest one. Second, a comparison of age groups 1 and 4 revealed a long-term increase, both in the overall sample and in each SES, of the form present in the input received by the children: i.e. the correctly produced liaison. The opposite trend was observed for the forms which are absent in the input: the number of replacement errors decreased for the overall sample and in both SES groups while the number of omission errors fell in the overall sample and in the lower-SES children. The omission error scores in the higher-SES children exhibited a more complex pattern, thus suggesting the presence of a regularization process with an increase followed by a decline.

\section{Results for variable liaisons}

\subsection{Correct production of variable liaisons}

With reference to the correct production of variable liaisons (Figure 4), SES significantly influenced children's scores $(\mathrm{F}(1,177)=9.67, \mathrm{p}=.0021)$, with the higher-SES children producing more adult-like realized liaisons than the lower-SES children. Although the global effect of age and the age by SES interaction were not significant (respectively, $p=.1267$ and $\mathrm{p}=.7061$ ), it should be noted that SES-related differences appeared only in the oldest age group $(\mathrm{p}=.0129)$ in which high-SES children produced nearly twice as many correct liaisons as low-SES children (40.7\% vs $21.1 \%)$. The social difference was not significant in age ranges 1 and $2(\mathrm{p}>.20)$, and was only marginally significant in age range $3(\mathrm{p}=.0645)$. Comparisons between range 1 and range 4 showed that the production of correct variable liaisons increased for the sample as a whole $(\mathrm{p}<.03)$ and for the higher-SES children $(p<.02)$ but not for lower-SES children $(p>.45)$. Indeed, the scores obtained by high-SES 
children doubled between the ages of 2-3 and 5-6 years $(\mathrm{p}<.02)$ whereas no clear development was observed for low-SES children.

Insert Figure 4 here

Figure 4 - Variable liaison: Evolution with age of correct productions in higher and lowerSES children (mean percentages + standard errors)

\subsection{Omission of variable liaisons}

It should be remembered that the omission of variable liaison is not a child error but one of the possible variants in adults. We observed no significant effect of $\operatorname{SES}(\mathrm{F}(1,177)=1.16$, $\mathrm{p}=.2821$ ) in the children in our sample (Figure 5). However, the effect of age was significant $(\mathrm{F}(3,177)=7.09, \mathrm{p}=.0001)$ as was the age by SES interaction $(\mathrm{F}(3,177)=3.51, \mathrm{p}=.0164)$. The differences between the social groups were not significant in age range $1(p>.95)$, were significant in age range $2(\mathrm{p}=.0292)$ and marginally significant in age range $3(\mathrm{p}=.0638)$. In the latter two groups, the higher-status children omitted more liaisons than the lower-status children. In age range 4 , the SES-related difference was marginally significant $(p=.0638)$ and we observed the reverse trend: omissions became more frequent in lower-SES children. This crossed pattern resulted from different evolutions with age in the two groups. In the higher-SES group, omissions increased between age ranges 1 and 3 (p =.006) and then stabilized between ranges 3 and 4 (p. > .5). The reverse was true in the lower-SES children: omission levels were constant between ranges 1 and $2(p>.756)$ and then increased between ranges 2 and $4(\mathrm{p}<.0001)$. A comparison of the omission rates between age ranges 1 and 4 , revealed that the values increased in the sample as a whole $(\mathrm{p}<.0001)$, as well as in the higher-SES $(\mathrm{p}<.04)$ and lower-SES $(\mathrm{p}<.0003)$ children.

Insert Figure 5 here

Figure 5 - Variable liaison: Evolution with age of omissions in higher and lower-SES children (mean percentages + standard errors)

\subsection{Replacement error for variable liaisons}

As far as replacement errors in variable liaisons are concerned (Figure 6), the effects of age $(\mathrm{F}(3,177)=22.64, \mathrm{p}<.0001)$ and $\operatorname{SES}(\mathrm{F}(1,177)=18.61, \mathrm{p}<.0001)$ were significant as was the interaction $(\mathrm{F}(3,177)=3.25, \mathrm{p}=.0230)$. The lower-SES children produced more 
replacement errors in the overall sample, in age ranges $2(\mathrm{p}=.0002)$ and $3(\mathrm{p}=.0001)$ but not in age ranges 1 and $4(p>.40)$. The decrease in the error rate between the age ranges 1 and 4 was significant for the overall sample ( $<$.0001), and for both the lower-SES $(\mathrm{p}<.0001)$ and higher-SES $(\mathrm{p}<.0001)$ children. However, the developmental changes were slightly different in the two SES groups. In the higher-SES children, the error rate declined between age ranges 1 and $2(\mathrm{p}=.004)$ but not between ranges 2 and $3(\mathrm{p}>.10)$ or between ranges 3 and 4 $(\mathrm{p}<.30)$. In the lower-SES children, the decrease appeared later. It was not significant between ranges 1 and $2(\mathrm{p}>.90)$, was marginally significant between ranges 2 and 3 ( $\mathrm{p}<$ $.088)$ and significant between ranges 3 and $4(\mathrm{p}<.0001)$. To summarize, the replacement error rates for the two social groups were very similar in age range 1. The higher-SES children began to eliminate the errors as of age range 2, whereas the lower-SES children did not do this until age range 3. Despite this differential development, both social groups achieved low replacement error rates by the end of the preschool years.

Insert Figure 6 here

Figure 6 - Variable liaison: Evolution with age of replacement error in higher and lower-SES children (mean percentages + standard error)

\subsection{Conclusion for variable liaison}

Regarding the production of correct variable liaisons, the SES-related differences became marginally significant in age group 3 and were significant in age group 4. Moreover, the scores increased with age in the higher-SES but not in the lower-SES children. All the indicators therefore suggest that SES-related differences in favor of higher-SES children appear late in development. The omission of variable liaisons is the second variant that children are exposed to. Whereas the omission scores increased at an early age in the higherSES children before leveling off, they increased late in lower-SES children and ultimately exceeded those observed in the other SES group. As was the case for the production of correct variable liaisons, we observed a late appearance of SES-related differences, with the omission scores becoming greater in the lower-SES children. Finally, the comparison between age group 1 and age group 4 revealed a long-term increase in the forms which are present in the input received by children: correct productions (in the sample as a whole and in the higherSES children) and omissions (in the sample as a whole and in both SES groups). In contrast, 
we observed a long-term fall-off in replacement errors (in the sample as a whole and in both SES groups) which children are not exposed to in the input they receive.

\section{Revisiting our predictions}

In the introduction, we formulated two types of prediction. The first type was based on the absence or presence of the different types of productions observed in children in the input heard by them. In each social group, we expected to observe an age-related increase in the three types of productions that are present in the input and observed in children - correct obligatory liaisons, correct variable liaisons and omissions of variable liaisons - and a reduction in the three types of production that are specific to children's speech - replacements of obligatory liaisons, replacements of variable liaisons and omissions of obligatory liaisons. The case of omissions is crucial here. Adults never produce a word1-word2 sequence without a liaison consonant if this constitutes an obligatory liaison context. The number of omissions should therefore decrease for obligatory liaisons and increase for variable liaisons.

In line with these predictions, the three types of production present in the input tended to increase with age. When we consider the sample as a whole, the number of correct obligatory liaisons, omitted variable liaisons and produced variable liaisons increased. This increase persisted in both SES groups in the case of correct obligatory liaisons and omitted variable liaisons. In the case of produced variable liaisons, the scores increased in the higher-SES children and remained constant in the lower-SES children. In contrast, the productions that are temporarily observed in children but are absent from the input tended to decrease with age. The number of replacements of obligatory liaisons and variable liaisons fell in the sample as a whole as well as in each SES group taken individually. Omissions of obligatory liaisons decreased for the sample as a whole and in the lower-SES children but not in the higher-SES children who already obtained low scores in the youngest age range. In these latter participants, a temporary increase at the age of 3-4 years suggests the presence of a regularization process. However, the general tendency observed for the overall sample with regard to liaison omissions confirms our predictions: the number of omissions fell for obligatory liaisons and increased for variable liaisons.

The second group of predictions related to the three types of production represented in the input. In line with our expectations, the changes in the SES-related differences in children's productions were seen to depend on the uniformity or, in contrast, the heterogeneity of usage in the different social groups. 
Since the obligatory liaisons that were observed are systematically produced by all adults, the children from both SES groups should ultimately use them in all instances. However, because higher-SES children receive a greater overall quantity of input (Hart and Risley, 2003; Hoff, 2003; Huttenlocher et al., 2007), they should possess the data necessary for this type of systematic production at an earlier age. This developmental offset should lead to early SES-related differences which subsequently disappear when this type of production also becomes systematic in lower-SES children. These expectations were confirmed by the results. The differences between the two SES groups were significant at 2-3 years but not at 5-6 years. As a result, the early SES-related differences in favor of higher-SES children tend to disappear during the course of development.

As far as variable liaisons are concerned, all the studies conducted in adults have shown that these are produced more frequently by higher-SES than by lower-SES speakers, while the opposite pattern has been observed for omissions (Ashby, 1981; Booij and De Jong, 1987; De Jong, 1991, 1994). Due to the competition between the two variants it is not possible to apply the same reasoning as for the obligatory liaisons here. During the period of acquisition, we expect that the availability of the two variants of variable liaisons will be modified as a function of their frequency in the input to which the children are exposed. As a result, the SES-related differences are expected to increase with age.

With reference to the correct production of variable liaisons, we saw that the difference between the two SES groups was not significant at either 2-3 years or at 3-4 years, was marginally significant at 4-5 years and significant at 5-6 years. Furthermore, the scores obtained by the higher-SES children increased significantly between 2-3 years and 5-6 years whereas they remained unchanged in the lower-SES children. As we predicted, the SESrelated differences increase during development. When we consider the omissions of variable liaisons, the pattern is more complex. The children in both SES groups exhibited very similar values at 2-3 years. Subsequently, the scores of the higher-SES children increased between the ages of 2-3 years and 4-5 years at which they exceeded those of the lower-SES children, and then remained constant between the ages of 4-5 and 5-6 years. For their part, the scores of the lower-SES children did not change between 2-3 years and 3-4 years and increased later, between the ages of 3-4 years and 5-6 years, when they exceeded those of the higher-SES children. This final pattern - more omissions in the lower-SES children - is the same as that observed in adults.

We need to account for the fact that the omission scores of the higher-SES children were temporarily greater than those of the lower-SES children. One possible explanation might take 
the form of an early effect of input quantity. Even if variable liaisons are omitted less frequently in the speech of higher-SES parents, the higher volume of input in this environment should mean that children in this group encounter these variants more frequently and learn them at an earlier age. However, this early effect of the quantity of input which contributes to the omission variant being learned by higher-SES children seems to be reduced later as the availability of the competing variants to children adjusts to the frequency with which they are encountered in the input. As a result, the scores for the omission of variable liaisons stop increasing between the ages of 4-5 years and 5-6 years in higher-SES children, while they continue to increase in lower-SES children. It is at this later age that the SESrelated differences observed in adults - more omitted variable liaisons in lower-SES individuals - become established in children.

It should be stressed that things are simpler when we turn to the produced variable liaisons. In effect, higher-SES parents produce this variant more frequently and provide a higher overall level of input. Taken together, these two reasons mean that their children hear more produced variable liaisons and learn these variants more quickly. In contrast, lower-SES parents produce variable liaisons less frequently and provide a lesser quantity of overall input. Their children therefore learn this variant later. The quantity and nature of the input therefore act in the same direction in terms of the production of variable liaisons whereas they act in opposite directions in terms of the omission of variable liaisons.

\section{Discussion and conclusion}

Liaison in French is a phonological alternation which is sometimes obligatory, and used in a uniform manner within the speech community, and sometimes variable, with the variants being more or less frequent depending on the speaker's SES. These two types of liaison perfectly illustrate two types of SES-related differences in the input received by children. The two observed variants of variable liaison - production and omission - illustrate the differences arising from pairs of competing forms whose frequencies vary depending on the parents' SES. The only observed variant of obligatory liaison - production - illustrates the differences resulting from a single linguistic form whose frequency in each SES group depends on the overall quantity of speech addressed to the child. The results suggest that the first type of difference in the input corresponds to differences in children's output which increase with age. Conversely, the second type of the difference in the input seems to correspond to output differences which decrease with age. Furthermore, we found that all the child forms that are absent from the input tend to become less frequent in the output as children get older. 
Conversely, the forms present in the input tend to become more prevalent in the output. We shall now discuss the causal nature of these correspondences between the input types and the development of children's productions. What factors other than the input might account for the differences observed in children's production of liaison and its changes during the course of development?

An initial alternative explanation relates to children's ability to adapt to formal situations. The results obtained by Chevrot et al. (2000) have shown that higher-SES children learn to adopt the standard variants of certain sociolinguistic variables in formal situations at an earlier age than lower-SES children. This tendency might explain the result patterns observed for the production of variable liaisons. In effect, a picture naming task with an unfamiliar experimenter might be perceived as a formal situation. Between the ages of 2 and 6 years, higher-SES children might learn to adjust the style of their language as a function of the situation, whereas lower-SES children would learn this behavior later. Consequently, and as we observed in our results, the frequency of produced variable liaisons would increase between these two ages in the former but not in the latter group. When applied to obligatory liaisons, this alternative explanation is unsatisfactory since these liaisons do not constitute a sociolinguistic variable.

The question is therefore whether the SES-related differences which appear between 2 and 6 years of age in the production of variable liaisons are still found in situations that are less formal than a picture naming task. Martin (2005) analyzed variable liaisons in utterances made by 24 children recorded over a period of 8 months during periods of non-directed play in the classroom. The children, whose mean age was $4 ; 5$ at the start of data collection and $5 ; 1$ at the end of this period, were recorded using wireless VHF microphones, after having been familiarized with the recording equipment and the presence of the researcher for a period of one month. For each child, Martin (2005) calculated an SES index based on the same classification of the two parents' occupations as was used in our experiment. The results revealed a very robust link between this SES index and the production rates for variable liaisons calculated for all the contexts in which this type of liaison may appear and not just in the adjective-noun context as in our picture naming task. The number of correct variable liaisons produced was significantly higher in the children with the highest family SES indexes. This difference continued to be significant when the children were contrasted on the basis of their father's or mother's SES index. Thus, within an age group corresponding to the last two age ranges in our sample (4-6 years), the SES-related differences observed in a picture naming task persisted during informal conversations between peers. It therefore seems 
difficult to attribute them to the different reactions of children from different social environments when faced with a formal situation.

A second alternative explanation relates to the awareness of the social value of the variants. Nardy (2008) asked 150 children aged 4 to 6 years to make judgments of the acceptability of nine known sociolinguistic variables associated with French phonology and morphosyntax. As of 4-5 years, the children's ability to recognize the value of the standard variant was significantly influenced by the socioprofessional category of the mother but not by that of the father. The children whose mothers had a higher professional status judged the standard variants more favorably and this difference persisted at the age of 5-6 years. This result indicates that higher-SES children are sensitive at an earlier age to the social value attributed to the two variants of a sociolinguistic variable. This might therefore represent a way of explaining the late appearance of SES-related differences in the task requiring the production of variable liaisons. Between the ages of 2 and 6 years, higher-SES children would discover that the production of variable liaisons is judged more favorably than their omission and this awareness would be mobilized in their own productions. Even though this reasoning cannot be applied unmodified to obligatory liaisons, which do not constitute sociolinguistic variables, a verification of the conformity of variable liaisons might be transferred to the obligatory liaisons. Only a small number of studies have examined the link between the production and judgment of sociolinguistic variables in children. In adults, the results combine to show that there is no direct relation between the way speakers judge a variant and the way they produce them. In effect, all the members of a speech community tend to judge the standard variants more highly irrespective of their own personal usage (Labov, 2001). In children, Chevrot et al. (2000) have observed that the age-related progress in stylistic adaptation between 6 and 12 years does not depend on an improvement in the ability to formulate judgments of acceptability concerning the variants. In effect, children exhibit adultlike situational adaptation in contexts where their judgments fail to differentiate between standard and non-standard variants. Conversely, whereas the ability to correctly evaluate the variants extends to certain phonological contexts in children from all the social environments, age-related progress in stylistic adaptation in the same contexts is observed only in the more privileged social group. Thus, between 6 and 12 years, the ability to favor the standard variants during production does not seem to be linked to the awareness of their social value. In younger children, such as those who participated in the present study, we cannot exclude the possibility that the link between judgment and production may be more direct and account for the SES-related differences in the production of liaisons. However, this seems unlikely 
given the level of metaphonological expertise involved which presupposes the ability to manipulate phonological alternations 'to order' as a function of a conceptual of a sociolinguistic norm.

The most direct interpretation of the age-related developmental patterns observed in our study is therefore to postulate that the learning of obligatory liaisons and variable liaisons is influenced by the quantity and nature of the input. The next step we must take in order to provide support for this hypothesis is to observe the way parents use liaisons in child-directed speech and establish a relation between this usage and the progress made by the children.

\section{Acknowledgments}

This research was supported by the program Apprentissages, Connaissances et Sociéte of the French National Agency for Research (ANR) and by the program Systèmes Complexes en Sciences Humaines et Sociales of the French Ministry of Research.

\section{References}

Ågren, J., 1973. Étude sur quelques liaisons facultatives dans le français de conversation radiophonique. Uppsala University Press, Uppsala.

Armstrong, N., 2002. Variable deletion of French ne: a cross-stylistic perspective. Language Sciences 24 (2), 153-173.

Ashby, W., 1981. French liaison as a sociolinguistic phenomenon. In: Cressey, W., Napoli, D. (Eds.), Linguistics Symposium on Romance Languages (9th). Georgetown University Press, Washington DC, pp. 46-57.

Boë, L.-J., Tubach, J.-P., 1992. 'De A à Zut': dictionnaire phonétique du français parlé. Ellug, Grenoble.

Booij, G., De Jong, D., 1987. The domain of liaison: theories and data. Linguistics 25 (5), 1005-1025.

Bornstein, M. H., Haynes, O. M., Painter, K. M., 1998. Sources of child vocabulary competence: a multivariate model. Journal of Child Language 25 (2), 367-393.

Cannard, C., Bonthoux, F., Blaye, A., Scheuner, A.-C., Trinquart, J., 2006. BD 21: normes sur l'identification de 274 images d'objets et leur mise en relation chez l'enfant français de 3 à 8 ans. L'Année Psychologique 106 (3), 375-396.

Chevrot, J.-P., Beaud, L., Varga, R., 2000. Developmental data on a French sociolinguistic variable: the word-final post-consonantal /R/. Language Variation and Change 12 (3), 295319. 
Chevrot, J.-P., Chabanal, D., Dugua, C., 2007. Pour un modèle de l'acquisition des liaisons basé sur l'usage: trois études de cas. Journal of French Language Studies 17 (1), 103-128.

Chevrot, J.-P., Dugua, C., Fayol, M., 2009. Liaison acquisition, word segmentation and construction in French: a usage based account. Journal of Child Language 36 (3), 557-596.

Coupland, N., 2007. Style. Language Variation and Identity. Cambridge University Press, Cambridge.

De Jong, D., 1991. La liaison à Orléans (France) et à Montréal (Québec). Actes du XIIe Congrès International des Sciences Phonétiques. Aix-en Provence, France, 198-201.

De Jong, D., 1994. La sociophonologie de la liaison orléanaise. In: Lyche, C. (Ed.), French Generative Phonology: retrospective and perspectives. Association for French Language Studies in association with the European Studies Research Institute, Salford, pp. 95-130.

Desrosières, A., Thévenot, L., 1988. Les catégories socioprofessionnelles. La Découverte, Paris.

Díaz-Campos, M., 2005. The emergence of adult-like command of sociolinguistic variables: a study of consonant weakening in Spanish-speaking children. In: Eddington, D. (Ed.), Selected proceedings of the 6th conference on the acquisition of Spanish and Portuguese as first and second Languages. Cascadilla Proceedings Project, Somerville, pp. 56-65.

Dollaghan, C. A., Campbell, T. F., Paradise, J. L., Feldman, H. M., Janosky, J. E., Pitcairn, D. N., Kurlasky, M., 1999. Maternal education and measures of early speech and language. Journal of Speech, Language, and Hearing Research 42 (6), 1432-1443.

Dugua, C., 2006. Liaison, segmentation lexicale et schémas syntaxiques entre 2 et 6 ans: un modèle développemental basé sur l'usage. Thèse de doctorat, Université Stendhal, Grenoble.

Durand, J., Lyche, C., 2008. French liaison in the light of corpus data. Journal of French Language Studies 18 (1), 33-66.

Green, J. N., Hintze, M.-A., 1990. Variation and change in French linking phenomena. In: Green, J. N., Ayres-Bennet, W. (Eds.), Variation and Change in French: essays presented to Rebecca Posner on the occasion of her sixtieth birthday. Routledge, London, pp. 61-88.

Hart, B., Risley, T. R., 2003. The early catastrophe: the 30 million word gap by age 3. American Educator 27 (1), 4-9.

Hoff, E., 2002. Causes and consequences of SES-related differences in parent-to-child speech. In: Bornstein, M. H., Bradley, R. H. (Eds.), Socioeconomic status, parenting and child development. Lawrence Erlbaum Associates, Mahwah, pp. 147-160.

Hoff, E., 2003. The specificity of environmental influence: socioeconomic status affects early vocabulary development via maternal speech. Child Development 74 (5), 1368-1378. 
Hoff, E., Laursen, B., Tardif, T., 2002. Socioeconomic status and parenting. In: Bornstein, M. H. (Ed.), Handbook of parenting. Lawrence Erlbaum Associates, Mahwah, pp. 231-252.

Huttenlocher, J., Vasilyeva, M., Cymerman, E., Levine, S., 2002. Language input and child syntax. Cognitive Psychology 45 (3), 337-374.

Huttenlocher, J., Vasilyeva, M., Waterfall, H. R., Vevea, J. L., Hedges, L. V., 2007. The varieties of speech to young children. Developmental Psychology 43 (5), 1062-1083.

Labov, W., 1964. Phonological correlates of social stratification. American Anthropologist 66 (6), 164-176.

Labov, W., 1972a. Language in the inner city: studies in the Black English Vernacular. Blackwell, Oxford.

Labov, W., 1972b. Sociolinguistic patterns. Blackwell, Oxford.

Labov, W., 2001. Principles of linguistic change, vol. 2: social factors. Blackwell, Oxford.

Lafontaine, D., 1986. Le parti pris des mots. Mardaga, Bruxelles.

Le Normand, M.-T., Parisse, C., Cohen, H., 2008. Lexical diversity and productivity in French preschoolers developmental and biosocial aspects by developmental, gender and sociocultural factors. Clinical Linguistics \& Phonetics 22 (1), 47-58.

Lucci, V., 1983. Étude phonétique du français contemporain à travers la variation situationnelle. Publications de l'Université des Langues et Lettres de Grenoble, Grenoble.

Martin, N., 2005. Réseaux sociaux et variations phonétiques. Mémoire de master 1, Université Stendhal, Grenoble.

Moisset, C., 2000. Variable liaison in Parisian French. Ph.D. dissertation, University of Pennsylvania, Philadelphia.

Nardy, A., 2008. Acquisition des variables sociolinguistiques entre 2 et 6 ans: facteurs sociologiques et influences des interactions au sein du réseau social. Thèse de doctorat, Université Stendhal, Grenoble.

Roberts, J., 1994. Acquisition of variable rules: (-t,d) deletion and (ing) production in preschool children. Ph.D. dissertation, University of Pennsylvania, Philadelphia.

Smith, J., Durham, M., Fortune, L., 2007. 'Mam, my trousers is fa'in doon!': community, caregiver and child in the acquisition of variation in a Scottish dialect. Language Variation and Change 19 (1), 63-99.

Sokal, R. R., Rohlf, J. F., 1981. Biometry: the principles and practice of statistics in biological research. W.H. Freeman and company, New York. 
Trudgill, P., 1975. Sex, covert prestige and linguistic change in the urban British English of Norwich. In: Thorne, B., Henley, N. (Eds.), Language and sex: difference and dominance. Newbury House Publishers, Rowley, pp. 88-104.

Trudgill, P., 1995. Sociolinguistics: an introduction to language and society (third edition). Penguin Books, London. 